

\section{Volatility Model Choice for Sub-Saharan Frontier Equity Markets - A Markov Regime Switching Bayesian Approach}

\section{Carl Hope Korkpoe Nathanial Howard}

\section{Introduction}

Investor interest in frontier equity markets of sub-Saharan Africa has been growing lately. This interest is topical in a growing finance and economics literature (Sukumaran, Gupta and Jithendranathan 2015; De Groot, Pang and Swinkels 2012; Quisenberry Jr and Griffith, 2010) and in International Finance Corporation (2013), the World Bank's private sector arm's newsletters for some time now. Bley and Saad (2012) suggest that, the principal motivation for this development is the low correlation of frontier market asset returns with their counterpart returns in the developed and emerging markets. However, perceived heightened risk is prevalent in the discussions related to investment and portfolio management activities in the frontier markets as a whole (Hassan, et al., 2003).

Much is known about volatility and the strategies for managing risks in investments in various assets in the developed and emerging markets. However, the same cannot be said for the smaller frontier markets which are ironically becoming important additions to portfolios of global investors seeking additional returns in the face of dwindling markets returns in the developed and emerging markets (Marshall, Nguyen and Visaltanachoti, 2013). The characteristics of these frontier markets are quite different from the emerging and developed market counterparts. For one thing, investors in frontier markets are starved of information about the markets they invest in (Sukumaran, Gupta and Jithendranathan, 2015). In equities markets, there are still problems of corporate governance of the listed firms and also insider market transactions, which are shrouded in secrecy (La Porta, et al. 2000, Klapper and Love, 2004). Besides, frontier economies are prone to bouts of uncertainty, foreign exchange crises, changing capital market regulations and at times political upheavals. One, therefore, will expect these to be transmitted to the broad asset markets as regime changes in market outcomes.

Externally, global developments influence the dynamics of economic activity in much of the developing world where some of these frontier markets are located. For long, a key factor that roils markets in emerging and frontier markets is US monetary policy and the demand for commodities from the developed world and China. A surge in the value of the US dollar normally causes a fall in the equities of the smaller markets of the frontier economies as global investors rebalance their portfolio holdings away from such markets towards profitable opportunities in developed markets. In the process, there is a surge in volatility of frontier market equities. The aversion for frontier market equities is further strengthened if the developed country economies are growing robustly.

The environment, therefore, generating the market data is influenced by economic, social and political developments which are in a continuous flux across time. These should determine the magnitude and the associated fluctuations of the asset returns conditional on the regimes generating the data. Modeling the volatility of stock market returns using regime switching is therefore motivated by these developments in the underlying economy.

Volatility modeling incorporating regimes have been studied extensively across the developed and emerging markets in various asset classes starting with the pioneering efforts of Hamilton (1989). Subsequent to this, Hamilton and Susmel (1994) and Hamilton (1996) gave additional insights into the behavior of returns using extensive economic data. Other authors, for example, Hardy (2001) and Gray (1996) have utilized regime switching models in equities and interest rates respectively and they have concluded that such models provide a better fit to the data than single regime GARCH models. In the emerging markets, the first attempt at characterising the volatility of market returns with regime switching models was by Assoe (1998). He assigned changing government policies and reforms in capital markets as the main factors driving regime changes in emerging markets. Since then, a number of papers have appeared in the literature identifying regimes in the returns of various assets in emerging markets (Ozdemir and Akgul 2015; Van Gysen, Huang and Kruger 2013; Li, 2013).

In contrast, academic research on frontier markets has focused little attention on the exploration of volatility behavior using regime switching models. The little there is incorporating regime-switching in volatility models is concentrated in the Gulf and North Africa regions. Balcilar et al. (2013), for example investigated herd behaviour among investors in the Gulf Arab stock markets and incorporated regime switching into the analysis. Samarakoon (2011) and Khalifa, Hammoudeh and Otranto (2014) looked at the spillover effects of the recent US financial crisis on emerging markets using regime switching. Charfeddine and Ajmi (2013) used regime switching to capture long memory effects on market returns on the Tunisia Stock Exchange. Still, Aloui, Hammoudeh \& Hamida (2015) adopted a regime switching approach to investigate the relationship between Sharia stocks and sukuk. For much of the frontier markets south of the Sahara, our search of the literature on Google Scholar did not reveal any such papers. Single regime GARCH models are the principal tools of choice for volatility modeling in the frontier markets in sub-Saharan Africa. Some recent papers are Carsamer (2016), Uyaebo, Atoi and Usman (2015), Chinzara and Slyper (2013), Esman Nyamongo and Misati (2010), Adjasi (2009), among others.

There is plenty of evidence in the finance literature suggesting that multi-regime volatility models provide a better description for modelling asset returns. Lamoureux, and Lastrapes (1990) investigated the 
performance of GARCH models in financial markets and concluded that they perform poorly in the face of changing regimes in the data. They attributed this to lack of fit of the models to the data. Single-regime volatility GARCH models are slow to react to changes in the returns structure that results from the sudden, albeit, inevitable changes that buffet the economy; hence the data generating process. Such changes in regimes are observed empirically. Regime switching models, thus, serve to capture the resulting rich heteroscedastic dynamics.

The clearest evidence of the presence of market regimes is the behaviour of the stock market during a recession vis-a-vis during an expansion in the economy. Standard GARCH models do not staircase risk across time, effectively discounting the empirical evidence of the behavior of equity prices in periods of recessions and expansions alternately. During recessions, nervous investors flee the equity markets to the safety of sovereign instruments. The reverse is seen in economic expansions. Thus, characterising the risks in the financial markets cannot be divorced from the underlying dynamics at play in the economy especially in measures of volatility, a pure financial construct for risk. Regime switching models are therefore seen as providing sound econometric explanation to the empirics of volatility in equity markets. Marcucci (2005) demonstrated the superiority of Markov switching GARCH models over all standard classes of GARCH models in use by examining the volatility of US stock markets returns.

Accurately estimating volatility in equity markets is important in more ways than one. Equities are now tied to many financial products in the market for assets. Thus, any jolt in equities roils all assets creating feedback loops which unsettle investors and spark more selling into falling markets, exacerbating volatility even further (Shleifer and Vishny, 2011). Models that provide the flexibility to adapt to changing market outcomes or regimes provide investors with tools to position trading strategies that avoid losses during market downturns. Single regime models lack this flexibility as a result of few parameters in their specification. This causes overfitting of the data (Cheng, Yu and Li, 2009) and predictably breakdowns in the face of regime changes in the underlying data generating process.

This study, therefore, seeks to identify appropriate regime switching models that correctly characterize the volatility dynamics of returns of selected sub-Saharan frontier market equities and also serve as the basis of forecasting risks in such markets. We used a sample of daily returns of the broad market indices of Ghana, Nigeria, Kenya and Botswana stock exchanges from January, 2011 to December, 2017 for our models. Using a number of popular regime switching models in the finance literature, we estimated the volatility of the returns of these indices as regime switching Markov volatility models. We used the Bayesian Monte Carlo simulation to get round the path dependency problem identified in Augustyniak (2014) and Hahn et al. (2010). We backtested the results for accuracy of the tail forecasts with value-at-risk methodologies. The following are our findings.

Sub-Saharan frontier equity markets are not homogeneous. Different regime-switching GARCH models describe the heteroscedastic behavior of all the market returns and with varying tail behaviour for the respective markets. The data generation processes of the returns are characterized by fat-tails. This can be a source of profitable opportunities at the same time risk of extreme losses for the investing community.

We make two important contributions to the literature on volatility in sub-Saharan frontier equity markets. First, we fill the void in the literature and provide concrete evidence of volatility regimes of market outcomes in the equity markets of sub-Saharan Africa. Investors have a guiding model to use in quantifying the evolving heteroscedastic risk with regime changes in frontier equity markets. This is true particularly for active managers implementing volatility-sensitive trading strategies who might seek to profit from market gyrations. Secondly, the paper provides a volatility model for monitoring regime changes in the volatility of returns in the frontier markets studied. This is fundamental to investment and portfolio management in the information starved environment of sub-Saharan frontier equity markets.

The progression of the rest of the paper is as follows: Section two looks at the regime-switching GARCH models employed in the study. An explanation of the Bayesian methodology is provided in section three. We undertake the analysis of the data in section four and make a decision on the appropriate regime switching model that provides the best fit to our respective sample data. A summary of the findings goes into section five. We backtest our result to assess model fit and the ability to forecast accurately in section six. Section seven concludes the paper.

\section{Model}

We denote the market returns by $\left[r_{\mathrm{t}}\right]_{1}^{\mathrm{T}}$ where $r_{t}=\operatorname{In}\left(\frac{p_{t}}{p_{t-1}}\right)$ is the $\log$ returns calculated from the closing prices $\mathrm{p}_{\mathrm{t}}$ on day $\mathrm{t}$. Adapting the notation of Ardia et al. (2018), the evolution of the volatility of returns in regime $\mathrm{k}$ given the information set at a time $\mathrm{t}-1, \mathcal{F}_{\mathrm{t}-1}$, parameters $\sigma_{\mathrm{k}, \mathrm{t}}^{2}$ and $\Xi_{\mathrm{k}}$, the Markov regime switching $\mathrm{GARCH}$ is generally stated as:

$\mathrm{r}_{\mathrm{t}} \mid\left(\mathrm{S}_{\mathrm{k}}, \mathcal{F}_{\mathrm{t}-1}\right) \sim \mathfrak{D}\left(0, \sigma_{\mathrm{k}, \mathrm{t}}^{2}, \Xi_{\mathrm{k}}\right)$

$\mathfrak{D ( . )}$ represents a mean zero continuous distribution with a time-varying variance $\sigma_{\mathrm{k}, \mathrm{t}}^{2}$ in regime $\mathrm{k}$ and parameter $\Xi_{\mathrm{k}}$, a vector describing the shape of the distribution. The Markov model assumes that $S_{k}$ is a discrete unobserved variable of the regimes taking values in the vector space $\{1,2, \ldots, \mathrm{k}\}$.

\section{Heteroscedastic Models}

The modified heteroskedastic functions incorporating regime changes are based on the specifications of Haas, Mittnik and Paolella (2004) as:

The GARCH Model

The GARCH $(1,1)$ of Bollerslev (1986) is:

$\sigma_{k, t}^{2}=\omega_{k}+\alpha_{k} r_{t-1}^{2}+\beta_{k} \sigma_{k, t-1}^{2}$ 
The parameters $\omega_{\mathrm{k}}, \alpha_{\mathrm{k}}$ and $\beta_{\mathrm{k}}$ are constrained as $\omega_{\mathrm{k}}>0, \alpha_{\mathrm{k}}>0$ and $\beta_{\mathrm{k}} \geq 0$ to ensure a positive variance. An additional constraint is $\alpha_{\mathrm{k}}+\beta_{\mathrm{k}}<1$ to guarantee regime $\mathrm{k}$ piecewise covariance stationarity.

\section{The EGARCH Model}

The EGARCH model was proposed by Nelson (1991) to capture the leverage effect identified in Black (1976). The model is specified as:

$\operatorname{In}\left(\mathrm{h}_{\mathrm{k}, \mathrm{h}}\right)=\omega_{\mathrm{k}}+\alpha_{1, \mathrm{k}}\left(\left|\xi_{\mathrm{k}, \mathrm{t}-1}-\mathrm{E}\left[\left|\xi_{\mathrm{k}, \mathrm{t}-1}\right|\right]\right|\right)+$

$\alpha_{2, \mathrm{k}} \mathrm{y}_{\mathrm{t}-1}+\beta_{\mathrm{k}} \operatorname{In}\left(\mathrm{h}_{\mathrm{k}, \mathrm{t}-1}\right)$

where $E\left[\left|\xi_{k, t-1}\right|\right]$ is the expectation conditional on a given regime $\mathrm{k}$. To ensure that a given regime $\mathrm{k}$ is stationary, we impose the restriction $\beta_{\mathrm{k}}<1$.

\section{The GJR-GARCH Model}

Glosten et al. (1993) proposed the GJRGARCH model to capture the asymmetry stylized fact of financial time series. This model is stated as:

$\sigma_{k, t}^{2}=\omega_{k}+\left(\alpha_{1, k}+\alpha_{2, k} \mathrm{I}_{\left\{y_{t-1<} 0\right\}}\right) \varepsilon_{t-1}^{2}+\beta_{k} \sigma_{k, t-1}^{2}$,

with I(.) an indicator function taking a value 1 if the condition is true and 0 otherwise.

The joint distribution of the regimes, $\mathrm{S}_{\mathrm{K}}$, is given by:

$p\left(S_{1}, S_{2}, \ldots, S_{K}\right)=$

$p\left(S_{1}\right) p\left(S_{2} \mid S_{1}\right) \ldots p\left(S_{k} \mid S_{1}, S_{2}, \ldots, S_{k-1}\right)$

which becomes

$p\left(S_{1}, S_{2}, \ldots, S_{K}\right)=p\left(S_{1}\right) \prod_{t=2}^{K} p\left(S_{t} \mid S_{t-1}\right)$

as the first-order Markov model. For two-regime states, $S_{1}$ and $S_{2}$, we define the transition matrix $p_{i j}$ as:

$p\left(S_{t+1}=j \mid S_{t}=i\right)=p_{i j}=\left[\begin{array}{ll}p_{11} & p_{12} \\ p_{21} & p_{22}\end{array}\right]$.

\section{Bayesian Parameter Estimation via MCMC}

Let the parameter space be $\Phi=\left\{\omega, \alpha, \beta, \sigma^{2}, v, \Pi_{\mathrm{ii}}\right\}$ and $\mathrm{S}=\left\{\mathrm{S}_{1}, \mathrm{~S}_{2}, \ldots, \mathrm{S}_{\mathrm{K}}\right\}$. We derive the posterior as joint distribution of the parameters conditional on the returns $r_{t}$. Invoking Bayes' rule and the conditional probability property, we write the joint distribution for the posterior as follows:

$$
\begin{aligned}
& p\left(\Phi, S_{t} \mid r_{t}\right) \propto p\left(\Phi, S_{t}\right) p\left(r_{t} \mid \Phi, S_{t}\right) \propto \\
& p(\Phi) p\left(S_{t} \mid \Phi\right) p\left(r_{t} \mid \Phi, S_{t}\right) .
\end{aligned}
$$

The first term, $\mathrm{p}(\Phi)$, on the right hand side is the prior specifying the hyperparameters of the distribution. This prior is expanded further as:

$p(\Phi)=$ $p(\omega) p(\alpha \mid \omega) p(\beta \mid \omega, \alpha) p\left(\sigma^{2} \mid \omega, \alpha, \beta\right) p\left(v \mid \omega, \alpha, \beta, \sigma^{2}\right) p($ becomes:

Using the assumption of independence, (9)

$$
p(\Phi)=p(\omega) p(\alpha) p(\beta) p\left(\sigma^{2}\right) p(v) p\left(\Pi_{i i}\right) \text {. }
$$

Das and Yoo (2004) and Kim and Nelson (1999) suggested normal priors for $\omega, \alpha$ and $\beta$. Ardia and Hoogerheide (2010) used truncated normal distributions to specify the priors for these GARCH parameters in order to maintain the constraints required for the variance to be positive. This approach is what we adopt in this paper. We specify an inverse gamma distribution for the variance, $\sigma^{2}$, as:

$\sigma^{2} \sim I G(\alpha, \beta)$

where $\alpha$ and $\beta$ are the respective shape and scale parameters of the inverse gamma distribution.

The full conditional density of the posterior is complicated and unknown a priori, so we adopt the Metropolis-Hastings (Hastings 1970; Metropolis, et al., 1953) algorithm of the MCMC for our posterior simulation.

\section{Data and Analysis}

Data for our analysis came from Botswana, Ghana, Kenya and Nigeria bourses. These countries were selected to reflect the regional groupings of west, east and southern African frontier equity markets based on the classification of MSCI Frontier Index (2019). Nigeria was added to the countries, because it has the most thriving equity market in sub-Saharan Africa classified as frontier. Our sample is made up of the respective broad market daily index from January 04, 2011 to December 29,2017 . Figure 1 plots the evolution of the levels of the indices.
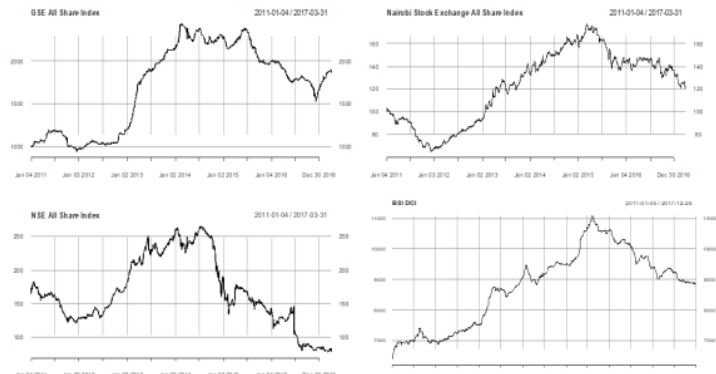

Figure 1. Evolution of Indices of the Stock Exchanges

Of the four indices, the Nigeria Stock Exchange (hereafter NSE) index shows more gyrations culminating in a sharp market correction mid-2015. The index has been on a downward trend since. The Ghana Stock Exchange (hereafter GSE) index rose in the mid2011 before touch a low point at the end of 2011. It then rose sharply until it peaked in the first quarter of 2014. It stayed roughly at this level until mid-2015 when it took a nose-dived and trended downward in a sustained manner till the last quarter of 2016 when it bottomed out. The Nairobi Stock Exchange (hereafter Nairobi) index level fell persistently in 2011 till the beginning of 2012 when it climbed steadily eventually peaking in the first quarter of 2015. It has since seen a sustained fall. The Botswana Stock Exchange (hereafter BSI DCI) index trended $\beta$, opywa)ds albeit bobbing up and down to about the beginning of the first quarter of 2015 when it started falling and has been on that trajectory up to the end of our sample period.

We plotted the log-returns of the various indices in Figure 2. 

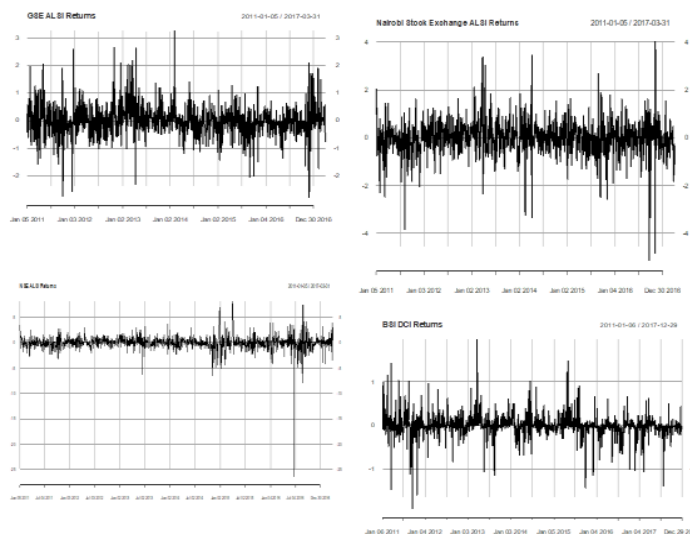

\section{Figure 2. The Log-Returns of the Broad Market Indices}

The returns of the four indices have been generally volatile during the sample period. Day-to-day returns of the BSI DCI, GSE and Nairobi have gyrated more wildly than the NSE. Volatility clusters characterize the returns of the GSE and Nairobi index returns compared to the NSE returns. On occasion, however, NSE has seen extreme outcomes. For example, mid-2016 saw the market return hitting close to $-27 \%$. The BSI DCI exhibits frequent turbulence during the period with negative returns mostly.

A summary of the statistics of the returns is provided in Table 1.

Table 1: Summary Statistics of the Returns of the Indices

\begin{tabular}{lrrrrrr}
\hline & 1st Quartile & Median & 3rd Quartile & Variance & Skewness & Kurtosis \\
\hline GSE & -0.21878 & -0.02579 & 0.192384 & 0.290331 & 0.380422 & 5.540297 \\
NSE & -0.50921 & 0.014576 & 0.581374 & 2.008498 & -4.33275 & 80.7575 \\
Nairobi & -0.34509 & 0.008772 & 0.369478 & 0.502662 & -0.53466 & 6.586665 \\
BSI DCI & -0.06203 & -0.012773 & 0.063659 & 0.056349 & -0.030498 & 14.288984 \\
\hline
\end{tabular}

The results in Table 1 show varying degrees of deviation of the returns from normality. In particular, the tails of the distributions are fat with the severity exhibited by the returns from the NSE. Additionally, the returns from all the markets with the exception of the GSE are left skewed.

We plotted the returns to visually assess how far the returns deviate or otherwise conform to the Gaussian distribution. This is shown in Figure 3.
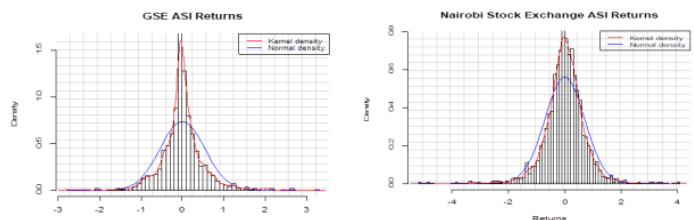

Reurno
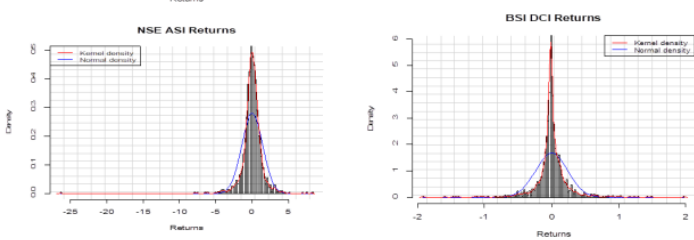

Figure 3. Histograms of Log-Returns with Kernels and Normal Density Curves Superimposed
In all cases, the returns seem to deviate from the normal density (in blue) superimposed on the distributions. Extreme outcomes are common. The returns for the NSE are within a narrow range, but with extreme outcomes. The tails exhibit heavier tails than normal in all cases with the severity of extremes much pronounced for the BSI DCI. This is confirmed by the summary statistics in Table 1.

A formal Shapiro-Wilk test for normality returned the $\mathrm{W}$-statistics and the corresponding $\mathrm{p}$-values shown in Table 2.

Table 2: Result of the Shapiro-Wilks Test

\begin{tabular}{lrl}
\hline Index & W-statistics & p-value \\
\hline GSE & 0.9057 & $<2.2 \mathrm{e}-16$ \\
NSE & 0.76805 & $<2.2 \mathrm{e}-16$ \\
Nairobi & 0.93099 & $<2.2 \mathrm{e}-16$ \\
BSI DCI & 0.78162 & $<2.2 \mathrm{e}-16$ \\
\hline
\end{tabular}

Using a significant level at the conventional $5 \%$, we reject the null hypothesis of each of the returns being normally distributed.

Markov switching models are built from GARCH primitives, so we tested for the presence of (G)ARCH effects using Engle's LM test (Engle, 1982). Under this test, in finite samples, the null hypothesis states that the residuals of a return series exhibits no $\mathrm{ARCH}$ effects, against the alternative that $\mathrm{ARCH}$ effects are present in the residuals. The test results are summarized in Table 3.

Table 3: Engle's LM Test for (G)ARCH Effects

\begin{tabular}{lccc}
\hline & $\chi^{2}$ & Lags & p-value \\
& & & \\
\hline GSE & 170.78 & 12 & $<2.2 \mathrm{e}-16$ \\
NSE & 458.94 & 12 & $<2.2 \mathrm{e}-16$ \\
Nairobi & 221.95 & 12 & $<2.2 \mathrm{e}-16$ \\
BSE & 20.64 & 12 & 0.056 \\
\hline
\end{tabular}

From Table 3, there are clearly ARCH effects in the returns series of the GSE, NSE and Nairobi at the $5 \%$ significance level. The ARCH effects in BSI DCI returns are just borderline at 5\% significant level.

We built the regime switching models for single- and two-state regime-switching GARCH models. The GARCH models considered are the normal GARCH, the EGARCH and GJR-GARCH for the skewed and student-t innovations. These are the GARCH models popular in the finance literature for volatility modeling. In all, we have twelve models to choose from. We employed the MSGARCH package developed by Ardia et al. (2016) using the $\mathrm{R}$ statistical language ( $\mathrm{R}$ Core Team, 2018). The Deviance Information Criterion (DIC) served as a basis in selecting the best fitting GARCH model to the data. The results of the analyses are displayed in Table 4 and 5.

The respective selected models for the various stock exchanges with the minimum Deviance 
Information Criteria (DIC) of Spiegelhalter et al. (2002) have been highlighted in Table 4 and 5 .

Table 4: DICs for Two-State Regime Switching GARCH Models

\begin{tabular}{|c|c|c|c|c|c|c|}
\hline \multirow[b]{3}{*}{ Exchange } & \multicolumn{6}{|c|}{ 2-state Regimes } \\
\hline & \multicolumn{3}{|c|}{ skewed student-t innovations } & \multicolumn{3}{|c|}{ student-t innovations } \\
\hline & GARCH & EGARCH & GJR-GARCH & GARCH & EGARCH & GJR-GARCH \\
\hline $\begin{array}{l}\text { Ghana Stock } \\
\text { Exchange }\end{array}$ & 1841.7294 & 1840.3798 & 1824.6506 & 1854.6183 & 1854.1435 & 1853.6957 \\
\hline NSE & 4454.2572 & 4439.5622 & 4446.1056 & 4437.8294 & 4443.1074 & 4431.538 \\
\hline Nairobi & 2888.6255 & 2872.5419 & 2893.9435 & 2892.6311 & 2890.255 & 2891.0432 \\
\hline BSIDCI & 1425.7972 & 1409.9006 & 1413.6385 & 1429.5611 & 1426.2381 & 1446.3622 \\
\hline
\end{tabular}

Table 5: DICs for Single-State Regime Switching GARCH Models

\begin{tabular}{lrlrrrr}
\hline \multicolumn{7}{c}{ Single-state Regime } \\
\hline & Skewed student-t innovations & \multicolumn{3}{c}{ student-t innovations } \\
\hline Exchange & GARCH & EGARCH & GJR-GARCH & GARCH & EGARCH & GJR-GARCH \\
\hline Ghana Stock & 1923.2698 & 1914.7429 & 1929.4702 & 1927.9081 & 1919.195 & 1931.0145 \\
Exchange & 4453.936 & 4461.8615 & 4455.3482 & 4453.0384 & 4464.3497 & 4455.386 \\
\hline NSE & 2885.9554 & 2892.2825 & 2885.7662 & 2885.8776 & 2894.3131 & 2887.1683 \\
\hline Nairobi & 1559.9982 & 1529.0363 & 1537.8687 & 1672.2747 & 1695.9763 & 1671.4365 \\
\hline BSI DCI & & & & & &
\end{tabular}

Overall, the 2-state regime-switching GARCH models fit the returns better than the single-regime models. For the aggregate market index of Ghana, the fitting model is the 2-state regime switching GJR$\operatorname{GARCH}(1,1)$ with skewed student-t innovations. This would suggest asymmetry in response to shocks. The NSE returns are best described by a 2-regime GJR$\operatorname{GARCH}(1,1)$ with student-t shocks. The Nairobi and Botswana bourses have returns during this sample period well described by 2-state regime switching $\operatorname{EGARCH}(1,1)$ with skewed student-t innovations. This shows the dominance of leverage effects in these markets.

\section{Model Diagnosis}

Results of the posterior estimates are reported in Tables 6, 7, 8 and 9 for GSE, BSI, NSE and Nairobi respectively. We assess the efficiency of the sampling method using the relative numerical efficiency (RNE) (Geweke, 1989). There are no clear guidelines in literature on the cut-off for an efficient RNE. Values close to one are efficient while those close to zero are an indication of working with non-independent samples. From the Tables 6-9, the values of RNE are low but not zero and so some degree of efficiency is achieved in our sampling.
Table 6: Estimates for the 2-State Regime GJRGARCH with Skewed Student-t Innovations - GSE

\begin{tabular}{crrrrr}
\hline Estimate & Mean & SD & SE & TSSE & RNE \\
\hline$\alpha_{01}$ & 0.0059 & 0.0177 & 0.0006 & 0.002 & 0.0772 \\
$\boldsymbol{\alpha}_{11}$ & 0.0519 & 0.0582 & 0.0018 & 0.0061 & 0.0907 \\
$\boldsymbol{\alpha}_{21}$ & 0.0001 & 0 & 0 & 0 & 0.0849 \\
$\boldsymbol{\beta}_{1}$ & 0.9273 & 0.077 & 0.0024 & 0.0078 & 0.0973 \\
$\boldsymbol{\nu}_{1}$ & 2.4927 & 1.3135 & 0.0415 & 0.1326 & 0.0981 \\
$\boldsymbol{\xi}_{1}$ & 1.2858 & 0.1391 & 0.0044 & 0.0141 & 0.0969 \\
$\boldsymbol{\alpha}_{02}$ & 0.0564 & 0.0242 & 0.0008 & 0.0022 & 0.1232 \\
$\boldsymbol{\alpha}_{12}$ & 0.2568 & 0.0887 & 0.0028 & 0.0095 & 0.0881 \\
$\boldsymbol{\alpha}_{22}$ & 0.0001 & 0 & 0 & 0 & 0.1305 \\
$\boldsymbol{\beta}_{2}$ & 0.6762 & 0.1091 & 0.0034 & 0.0108 & 0.1018 \\
$\boldsymbol{\nu}_{2}$ & 5.6411 & 1.7633 & 0.0558 & 0.1769 & 0.0994 \\
$\xi_{2}$ & 1.0787 & 0.053 & 0.0017 & 0.0032 & 0.2721 \\
$\boldsymbol{p}_{11}$ & 0.4942 & 0.1062 & 0.0034 & 0.0095 & 0.1257 \\
$\boldsymbol{p}_{21}$ & 0.2577 & 0.0531 & 0.0017 & 0.0052 & 0.1029 \\
\hline & & & & &
\end{tabular}

Table 7: Estimates of 2-State Regime E-GARCH with Skewed Student-t Innovations - BSI DCI

\begin{tabular}{crrrrr}
\hline Estimate & Mean & SD & SE & TSSE & RNE \\
\hline$\alpha_{01}$ & 0.6823 & 0.0484 & 0.0015 & 0.0201 & 0.0058 \\
$\boldsymbol{\alpha}_{11}$ & 0.0056 & 0.0029 & 0.0001 & 0.0004 & 0.0438 \\
$\boldsymbol{\alpha}_{21}$ & 0.0028 & 0.0029 & 0.0001 & 0.0004 & 0.0526 \\
$\boldsymbol{\beta}_{1}$ & 0.8788 & 0.0086 & 0.0003 & 0.0035 & 0.0061 \\
$\boldsymbol{\nu}_{1}$ & 2.1001 & 0 & 0 & 0 & 0.0071 \\
$\boldsymbol{\xi}_{1}$ & 12.6066 & 0.7781 & 0.0246 & 0.2327 & 0.0112 \\
$\boldsymbol{\alpha}_{02}$ & 0.1752 & 0.0271 & 0.0009 & 0.0106 & 0.0066 \\
$\boldsymbol{\alpha}_{12}$ & 0.1533 & 0.0949 & 0.003 & 0.0152 & 0.039 \\
$\boldsymbol{\alpha}_{22}$ & 0.0247 & 0.0491 & 0.0016 & 0.0064 & 0.058 \\
$\boldsymbol{\beta}_{2}$ & 0.8568 & 0.0192 & 0.0006 & 0.0127 & 0.0023 \\
$\boldsymbol{\nu}_{2}$ & 2.1 & 0 & 0 & 0 & 0.0201 \\
$\boldsymbol{\xi}_{2}$ & 1.0532 & 0.021 & 0.0007 & 0.0013 & 0.2657 \\
$\boldsymbol{p}_{11}$ & 0.2955 & 0.0154 & 0.0005 & 0.0041 & 0.0139 \\
$\boldsymbol{p}_{21}$ & 0.1514 & 0.0098 & 0.0003 & 0.0029 & 0.0111 \\
\hline
\end{tabular}

Table 8: Estimates of 2-State Regime GJR-GARCH with Student-t Innovations - NSE

\begin{tabular}{crrrrr}
\hline Estimate & Mean & SD & SE & TSSE & RNE \\
\hline$\alpha_{01}$ & 0.2546 & 0.2829 & 0.0089 & 0.0567 & 0.0249 \\
$\alpha_{11}$ & 0.0453 & 0.1789 & 0.0057 & 0.0225 & 0.0634 \\
$\alpha_{21}$ & 0.1671 & 0.0699 & 0.0022 & 0.0116 & 0.0363 \\
$\beta_{1}$ & 0.608 & 0.2682 & 0.0085 & 0.053 & 0.0256 \\
$\boldsymbol{\nu}_{1}$ & 56.2918 & 46.9213 & 1.4838 & 10.7594 & 0.019 \\
$\alpha_{02}$ & 0.4048 & 0.9121 & 0.0288 & 0.2566 & 0.0126 \\
$\alpha_{12}$ & 0.1427 & 0.3016 & 0.0095 & 0.0644 & 0.0219 \\
$\alpha_{22}$ & 0.2081 & 0.1516 & 0.0048 & 0.0333 & 0.0208 \\
$\beta_{2}$ & 0.2012 & 0.291 & 0.0092 & 0.0525 & 0.0307 \\
$\boldsymbol{v}_{2}$ & 34.5793 & 40.0174 & 1.2655 & 5.4623 & 0.0537 \\
$\boldsymbol{p}_{11}$ & 0.8798 & 0.1535 & 0.0049 & 0.0427 & 0.0129 \\
$\boldsymbol{p}_{21}$ & 0.105 & 0.1296 & 0.0041 & 0.0327 & 0.0157 \\
\hline & & & & &
\end{tabular}


Table 9: Estimates of 2-State Regime E-GARCH with Skewed Student-t Innovations - Nairobi

\begin{tabular}{crrrrr}
\hline Estimate & Mean & SD & SE & TSSE & RNE \\
\hline$\alpha_{01}$ & 0.3758 & 0.0826 & 0.0018 & 0.004 & 0.2131 \\
$\boldsymbol{\alpha}_{11}$ & 0.5835 & 0.075 & 0.0017 & 0.0031 & 0.2923 \\
$\boldsymbol{\alpha}_{21}$ & 0.1666 & 0.0533 & 0.0012 & 0.0026 & 0.2164 \\
$\boldsymbol{\beta}_{1}$ & 0.3108 & 0.0738 & 0.0017 & 0.004 & 0.1723 \\
$\boldsymbol{\nu}_{1}$ & 4.5252 & 0.7315 & 0.0164 & 0.047 & 0.1212 \\
$\boldsymbol{\xi}_{1}$ & 0.8803 & 0.0349 & 0.0008 & 0.0018 & 0.1902 \\
$\boldsymbol{\alpha}_{02}$ & 0.5342 & 0.2606 & 0.0058 & 0.0174 & 0.1128 \\
$\boldsymbol{\alpha}_{12}$ & 0.4854 & 0.4251 & 0.0095 & 0.0443 & 0.0461 \\
$\boldsymbol{\alpha}_{22}$ & 0.3301 & 0.4066 & 0.0091 & 0.0342 & 0.0708 \\
$\boldsymbol{\beta}_{2}$ & 0.2913 & 0.0987 & 0.0022 & 0.0168 & 0.0172 \\
$\boldsymbol{\nu}_{2}$ & 2.102 & 0.001 & 0 & 0.0001 & 0.154 \\
$\boldsymbol{\xi}_{2}$ & 1.6521 & 0.1825 & 0.0041 & 0.0171 & 0.0569 \\
$\boldsymbol{p}_{11}$ & 0.981 & 0.0063 & 0.0001 & 0.0003 & 0.1634 \\
$\boldsymbol{p}_{21}$ & 0.096 & 0.0287 & 0.0006 & 0.006 & 0.0114 \\
\hline
\end{tabular}

\section{Discussion}

In all the exchanges studied, there is strong evidence that the statistical properties of the regimes are different, confirming the heterogeneous nature of the various markets as well as the regime switching nature of the volatility of returns.

\section{Ghana Stock Exchange}

The GARCH error terms are $\alpha_{11}=0.0519$ and $\alpha_{12}=0.2568$. The reaction of the conditional volatility to market shocks differs for the respective regimes. In the high volatility regime, investors react much more to market shocks than in the low volatility regime when market events are much more serene. This is expected naturally in the financial market as investors would react to any market news when they are jittery. The persistence of volatility as shown by the values of the GARCH lags $\beta_{k}$ also differs to both regimes. Volatility is much persistent in regime $1\left(\beta_{1}=0.9273\right)$ than in regime $2\left(\beta_{2}=0.6762\right)$. As pointed out by Alexander (2008), a $\beta$ above 0.9 is an indication that volatility takes a long time to die out following a market shock. Thus, the low regime volatility is persistent. This is in line with observations of thin and asynchronous trading on the GSE which effectively ensure that a given level of volatility is maintained for a long time. The unconditional volatility for regimes 1 and 2 are $3.01 \%$ and $13.06 \%$ respectively. The low volatility could be a reflection of lack of activity in most listed stocks.

The rate of convergence to the long term volatility for regime $1\left(\alpha_{11}+\frac{1}{2} \alpha_{21}+\beta_{1}=0.97925\right)$ is slightly faster than that of regime $2\left(\alpha_{12}+\frac{1}{2} \alpha_{22}+\beta_{2}=\right.$ 0.93305). Again, a low tail thickness value, $v_{1}=$ 2.4927, indicates that the distribution of the returns in regime 1 has thicker tails than regime 2 with $v_{2}=$ 5.6411. To summarize, both regimes are skewed $(\xi>0)$ with the tendency to remain in regime 1 rather dominant ( $p_{11} \approx 49 \%$ ). Regime 1 has a low reaction to past negative shocks with a high persistence in volatility. Regime 2 which is much more volatile with unconditional volatility of $18.5 \%$, tends to be short lived $\left(p_{22} \approx 25 \%\right)$ with low volatility persistence.

\section{Nigeria Stock Exchange}

The volatility dynamics of the Nigeria Stock Exchange is characterized by two regimes, each with a different unconditional volatility of $12.92 \%$ and $52.43 \%$. A dominant low regime has a probability of $87 \%$ and a high regime lasting approximately $10 \%$ of the time. The market shows a swift reaction to market shocks in the high volatility regime $\left(\alpha_{12}=0.1427\right)$ than in the low market regime $\left(\alpha_{11}=0.0453\right)$. Similar to the GSE, the persistence of the volatility indicated by the values of the GARCH lags $\beta_{\mathrm{k}}$ also differs by regimes. Volatility is persistent in regime $1\left(\beta_{1}=0.6008\right)$ compared to that in regime $2\left(\beta_{2}=0.2012\right)$. Here, the values of this GARCH estimate is less than the threshold of 0.9 indicating that volatility takes relatively short time to abate following a market disturbance.

The rate of convergence to the long term volatility for regime $1\left(\alpha_{11}+\frac{1}{2} \alpha_{21}+\beta_{1}=0.73685\right)$ is faster than that of regime $2\left(\alpha_{12}+\frac{1}{2} \alpha_{22}+\beta_{2}=\right.$ $0.44795)$. The distribution of the returns in the high volatility regime exhibits heavier tails $\left(v_{2}=34.5793\right)$ than the distribution in the low volatility regime $\left(v_{1}=\right.$ 56.2918). We summarise the heteroscedastic characterization of the NSE as having a swift reaction to market shocks in regimes with a longer time for volatility to die out in regime 1 . The low volatility regime is dominant with the high regime persisting only about $10 \%$ of the time.

\section{$B S I D C I$}

The volatility of the low regime of the BSI DCI index with an unconditional volatility of $10.49 \%$ is relatively longer (with a probability of $\mathrm{p}_{11}=0.2955$ ) than the high volatility regime (unconditional volatility of $23.74 \%$ ) with a probability of $\mathrm{p}_{11}=0.1514$. The regimes alternate after short periods. This is confirmed in the graph in Figure 2. The GARCH error parameters for regime 1 and regime 2 are $\alpha_{21}=0.0028$ and $\alpha_{22}=$ 0.0247 respectively. This is below the threshold of 0.1 stated in Alexander (2008). Thus, the market has different reactions to negative past returns but, it is very insensitive to market events. This observation could be due to the asynchronous and thin trading effects in much of the frontier markets of sub-Saharan Africa with a small number of institutional investors and market analysts keeping an eye on market developments. The rate of convergence of the volatility to its long term level is $\alpha_{11}+\frac{1}{2} \alpha_{21}+\beta_{1}=0.8858$ and $\alpha_{12}+\frac{1}{2} \alpha_{22}+\beta_{2}=$ 0.92245 , respectively, for the low and high regimes. The term structure of volatility for regime 2 is therefore relatively flat compared to regime 1 .

$$
\text { The tails of both regimes }
$$
$\left(v_{1}=2.1001\right.$ and $\left.v_{2}=2.1\right)$ are fat. This is supported by the histogram in Figure 3 of the returns of the BSI DCI index. Investors can therefore make rich pickings in the market with careful selection of equities. The shape of the distribution in regime 1 is relatively skewed $\left(\xi_{1}=\right.$ 
12.6066) compared with the almost symmetrical shape of regime $2\left(\xi_{2}=1.0532\right)$.

\section{Nairobi Stock Exchange}

The volatility of the market index in Nairobi in both regimes is very sensitive to past market events $\left(\alpha_{12}=0.5835, \alpha_{22}=0.4854\right)$. This might suggest an active market with lots of market analysts and seasoned or institutional investors. Unconditional volatility of regimes 1 and 2 respectively is $11.23 \%$ and $29.52 \%$. The distributions of returns are heavy-tailed in both regimes $\left(v_{1}=4.5252, v_{2}=2.102\right)$, suggesting the possibility of extreme returns for either regime. The volatility persistence across both regimes are similar, $\alpha_{11}+$ $\frac{1}{2} \alpha_{21}+\beta_{1}=0.9776$ and $\alpha_{12}+\frac{1}{2} \alpha_{22}+\beta_{2}=0.94175$. These values suggest that, volatility takes a long time to die out following a market jolt. The shape of the distribution parameters, $\xi_{1}=0.8803$ and $\xi_{2}=1.6521$ respectively for regimes 1 and 2 , suggest slight asymmetries in the distributions. In their work, Fernandez and Steel (1998) suggest $\xi=0$ for a symmetrical distribution.

The evolution of the conditional volatility for the four exchanges during the sample period is shown in Figure 4.

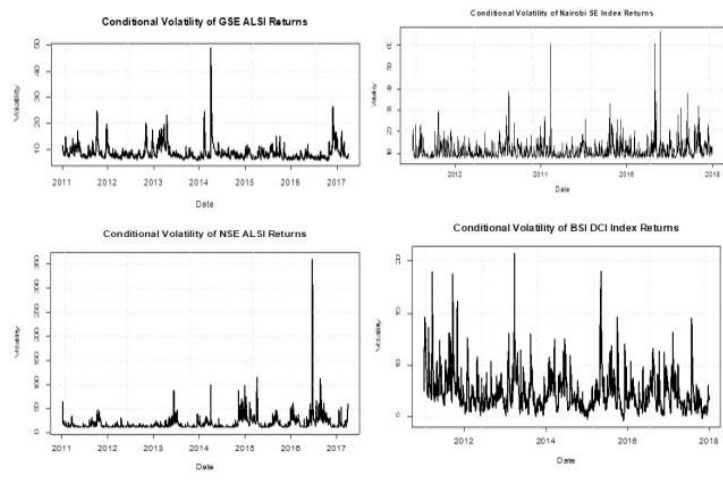

Figure 4. Conditional Volatility of the Index Returns of the Four Sub-Saharan Equities

For each of these countries, volatility surges are sharp, but revert quickly to moderate levels. The volatility uptick in most cases is clearly due to investor nervousness about developments in the underlying economy. For the most part, the effects of thin and asynchronous trading observed by Mlambo and Biekpe (2005) in most African equities is prevalent as seen in the dominance of low volatility regimes across the countries studied.

\section{Backtesting the Results}

We checked our results out-of-sample as a precaution against overfitting of the models to the data. Complex statistical models are notoriously prone to overfitting and perform poorly out-of-sample, where they are most relevant. Cawley and Talbot (2007) discuss extensively the problems particularly with Bayesian models in machine learning. We aim to assess the robustness of our models in predicting correctly the value-at-risk at the standard 5\% quantile. We utilized the conditional coverage test (CC) of Christoffersen (1998) and the dynamic quantile (DQ) test of Engle and Manganelli (2004). The CC test jointly tests for the independence (Kupiec 1995) and unconditional coverage (Christoffersen 1998) provided that, the VaR exceedances are independent and non-autocorrelated. Thus, the null hypothesis is that, exceedances are independent and are also derived from the conditional and unconditional coverage test statistics. The joint statistic has a $\chi^{2}$ distribution with one degree of freedom. The dynamic quantile (DQ) test of Engle and Manganelli for backtesting VaR models is a regression of the hit sequence, $I_{t}$, on a set of explanatory variables including the VaR quantiles and a finite number of lagged hits. The dynamic quantile test provides an overall goodness-of-fit test of the models under consideration.

We generated 700 samples ex-post for the 0.05 percentile of the returns from the model. The test covered the chosen regime switching model and its corresponding non-switching counterpart for each of the stock markets studied. The results are shown in Table 10.

Table 10: Results of Conditional Coverage and Dynamic Quantile Tests

\begin{tabular}{|c|c|c|c|}
\hline & & GJR-sstd & MS2-GJR-sstd \\
\hline \multirow[t]{3}{*}{ GSE } & CCp-value & 0.385839 & 0.7187228 \\
\hline & DQ p-value & 0.0919836 & 0.1127054 \\
\hline & & GJR-std & MS2-GJR-std \\
\hline \multirow[t]{3}{*}{ NSE } & CC $p$-value & $1.42382 \mathrm{E}-05$ & 0.0005318 \\
\hline & DQ p-value & 0.000096772 & 0.002668 \\
\hline & & EGARCH sstd & MS2-EGARCH sstd \\
\hline \multirow[t]{3}{*}{ Nairobi } & CC $p$-value & 0.524988 & 0.3983239 \\
\hline & DQ p-value & 0.3181468 & 0.525648 \\
\hline & & EGARCH-sstd & MS2-EGARCH-sstd \\
\hline \multirow[t]{2}{*}{ BSI DCI } & CCp-value & 0.002739376 & 0.105842966 \\
\hline & DQ p-value & 2.23E- 07 & 4.64E-04 \\
\hline
\end{tabular}

Results show a better model fit for the tworegime switching models for all exchanges, except the conditional coverage of Nairobi. The p-values of the DQ for the two-regime switching models are consistently higher than the single regime models. The conflicting finding of Nairobi has been discussed in the finance literature. Komunjer (2013) discussed at length the performance of these $\mathrm{VaR}$ tests and concludes that the dynamic quantile test by relying on out-of-sample simulations instead of the in-sample tests on which conditional coverage is based is a far more powerful test. We therefore conclude that, the two-regime Markov switching EGARCH for Nairobi is a better fit to the returns.

\section{Conclusion}

Financial markets are subject to the developments in the underlying economy, which ultimately transmits to regime changes in returns. As it is, single regime models do not track closely the changing variability between bull and bear markets 
observed in equity returns. Risk dynamics do change in response to the economies in which markets operate. For the sub-Saharan African equity markets with a dearth of market information to aid decision-making (Enisan and Olufisayo 2009), keeping an eye on the developments in the broader economy together with how this affects market returns should provide competitive advantage to investors. Estimating volatility using regime switching informs investing by using risk estimates, which fairly reflect existing market conditions through the responsiveness of the estimating models to risk.

As our study shows, sub-Saharan Africa frontier equity markets are far from homogenous. Different dynamics, be it social, political or economic, are the driving forces behind the financial markets in these countries. Single regime models are likely to under-or over-estimate risk during periods of high or low volatility respectively. Therefore, a granular approach to estimating volatility that we have done for these subSaharan frontier equity markets seem the most rational way market actors can fine-tune their investment strategies to avoid losses during high volatility periods. All the markets studied show clear regimes in market volatility with different statistical properties.

Again, it is clear that though these markets are classified in the same bracket of frontier markets, different dynamics are driving their heteroscedastic evolution. Different heteroskedastic functions with varied tail behavior described the return data of Ghana, Nigeria, Nairobi and Botswana stock indices with observed asymmetric and leverage effects in the markets. Investors therefore have to be alert to generalizations that most likely will not fit all markets. Optimal risk-based allocation of investing funds based on volatility regimes across these markets adds to the benefits of diversification in equities trading in sub-Saharan African equity markets. In addition, any future risk-based capital allocation such as for Value-at-risk or expected tail loss that is regime aware based on the findings in this study should lead to prudent risk management and control. In all the markets under study, the low volatility regime dominates, leaving brief spells of market turbulence. This will provide investors with the information to lean against the winds during brief market gyrations.

\section{References}

Adjasi, C. K. (2009). "Macroeconomic uncertainty and conditional stock-price volatility in frontier African markets: Evidence from Ghana." The Journal of Risk Finance 10, no. 4, 333-349.

Alexander, C. (2008). "Market Risk Analysis: Practical Financial Econometrics", (Vol. II), Hoboken: Wiley.

Aloui, C, S Hammoudeh, and H. B Hamida. (2015). "Price discovery and regime shift behavior in the relationship between sharia stocks and sukuk: A two-state Markov switching analysis." Pacific-Basin Finance Journal 34, 121-135.
Ardia, D, and L. F Hoogerheide. (2010). "Bayesian estimation of the garch $(1,1)$ model with student-t innovations." The R Journal 2, no. 2, 41-47.

Ardia, D, K Bluteau, K Boudt, and L Catania. (2018). "Forecasting Risk with Markov-Switching GARCH Models: A Large-Scale Performance Study." International Journal of Forecasting 34, no. 4, 733-747.

Ardia, D, K Bluteau, K Boudt, L Catania, and D.A Trottier. (2016). "Markov-Switching GARCH Models in R: The MSGARCH Package ." Journal of Statistical Software, Forthcoming.

Assoe, K.G. (1998). "Regime-switching in emerging stock market returns." Multinational Journal 2, 101-132.

Augustyniak, M. (2014). "Maximum likelihood estimation of the Markov-switching GARCH model." Computational Statistics \& Data Analysis 76, no. 1, 61-75.

Balcilar, M, R Demirer, and S Hammoudeh. (2013). "Investor herds and regime-switching: Evidence from Gulf Arab stock markets." Journal of International Financial Markets, Institutions and Money 23, 295-321.

Black, F. (1976). "Studies of Stock Price Volatility Changes." Proceedings of the 1976 Meetings of the Business and Economics Statistics Section. American Statistical Association, 177-181.

Bley, J, and M Saad. (2012). "Idiosyncratic risk and expected returns in frontier markets: Evidence from GCC." Journal of International Financial Markets, Institutions and Money 22, no. 3, 538-554.

Bollerslev, T. (1986). "Generalized autoregressive conditional heteroskedasticity." Journal of Econometrics 31, no. 3, 307-327.

Carsamer, E. (2016). "Volatility Transmission In Selected African Foreign Exchange Markets." International Journal of Economic Perspectives 10 , no. 2, 43-61.

Cawley, G. C, and N. L Talbot. (2007). "Preventing overfitting during model selection via Bayesian regularisation of the hyper-parameters." Journal of Machine Learning Research 8, April 2007, 841-861. 
Charfeddine, L, and A. N Ajmi. (2013). "The Tunisian stock market index volatility: Long memory vs. switching regime." Emerging Markets Review $16,170-182$.

Cheng, X, P. L Yu, and W. K Li. (2009). "On a dynamic mixture GARCH model." Journal of Forecasting 28, no. 3, 247-265.

Chinzara, Z, and S Slyper. (2013). "Volatility and anomalies in the Johannesburg Securities Exchange daily returns." Financial Markets Journal 17 , no. 1, 25-41.

Christoffersen, P. F. (1998). “ Evaluating interval forecasts." International Economic Review, 841-862.

Das, D, and B. H Yoo. (2004). "A Bayesian MCMC algorithm for Markov switching GARCH models." Econometric Society, 1-16.

De Groot, W, J Pang, and L Swinkels. (2012). "The cross-section of stock returns in frontier emerging markets." Journal of Empirical Finance 19, no. 5, 796-818.

Engle, R. F. (1982). "Autoregressive conditional heteroscedasticity with estimates of the variance of United Kingdom inflation." Econometrica: Journal of the Econometric Society, 987-1007.

Engle, R. F, and S Manganelli. (2004). "CAViaR: Conditional autoregressive value at risk by regression quantiles." Journal of Business \& Economic Statistics 22, no. 4, 367-381.

Enisan, A.A, and A.O Olufisayo. (2009). "Stock market development and economic growth: Evidence from seven sub-Saharan African countries." Journal of Economics and Business 61, no. 2, 162-171.

Esman Nyamongo, M, and R Misati. (2010). "Modelling the time-varying volatility of equities returns in Kenya." African Journal of Economic and Management Studies 1, no. 2, 183-196.

Fernández, C, and M. F Steel. (1998). "On Bayesian modeling of fat tails and skewness." Journal of the American Statistical Association 93, no. 441, 359-371.

Geweke, J. (1989). "Bayesian inference in econometric models using Monte Carlo integration." Econometrica: Journal of the Econometric Society, 1317-1339.
Glosten, L.R, R Jagannathan, and D.E Runkle. (1993). "On the Relation Between the Expected Value and the Volatility of the Nominal Excess Return on Stocks." Journal of Finance 48, no. 5, 1779-1801.

Gray, S. F. (1996). "Modeling the conditional distribution of interest rates as a regimeswitching process." Journal of Financial Economics 42, no. 1, 27-62.

Haas, M, S Mittnik, and M. S Paolella. (2004). "A new approach to Markov-switching GARCH models." Journal of Financial Econometrics 2, no. $4,493-530$.

Hahn, M, S Frühwirth-Schnatter, and J Sass. (2010). "Markov chain Monte Carlo methods for parameter estimation in multidimensional continuous time Markov switchingmodels." Journal of Financial Economics 8, no. 1, 88121.

Hamilton, J. D. (1989). "A new approach to the economic analysis of nonstationary time series and the business cycle." Econometrica: Journal of the Econometric Society, 357-384.

Hamilton, J. D. (1996). "Specification testing in Markovswitching time-series models." Journal of Econometrics 70, no. 1, 127-157.

Hamilton, J. D, and R Susmel. (1994). "Autoregressive conditional heteroskedasticity and changes in regime." Journal of Econometrics 64, no. 1-2, 307-333.

Hardy, M. R. (2001). "A regime-switching model of long-term stock returns." North American Actuarial Journal 5, no. 2, 41-53.

Hassan, M. K, N. C Maroney, H. M El-Sady, and A Telfah. (2003). "Country risk and stock market volatility, predictability, and diversification in the Middle East and Africa." Economic Systems 27, no. 1, 63-82.

Hastings, W. K. (1970). "Monte Carlo sampling methods using Markov chains and their applications." Biometrika 57, 97-109.

International Finance Corporation. (2013). Annual Report. Washington, D.C., USA: International Finance Corporation. 
Khalifa, A. A, S Hammoudeh, and E Otranto. (2014). "Patterns of volatility transmissions within regime switching across GCC and global markets." International Review of Economics \& Finance 29, 512-524.

Kim, C. J, and C. R Nelson. (1999). "Has the US economy become more stable? A Bayesian approach based on a Markov-switching model of the business cycle." Review of Economics and Statistics 81, no. 4, 608-616.

Klapper, L. F, and I Love. (2004). "Corporate governance, investor protection, and performance in emerging markets." Journal of Corporate Finance 10, no. 5, 703-728.

Komunjer, I. (2013). "Quantile Prediction". Vol. 2, in Handbook of Economic Forecasting, by G Elliott and A Timmermann, 961-994. Amsterdam: Elsevier.

Kupiec, P. H. (1995). "Techniques for Verifying the Accuracy of Risk Measurement Models." The Journal of Derivatives 3, no. 2, 73-84.

La Porta, R, F Lopez-de-Silanes, A Shleifer, and R Vishny. (2000). "Investor protection and corporate governance." Journal of Financial Economics 58, no. 1, 3-27.

Lamoureux, C. G, and W. D Lastrapes. (1990). "Persistence in variance, structural change, and the GARCH model." Journal of Business \& Economic Statistics 8, no. 2, 225-234.

Li, H. (2013), "Integration versus segmentation in China's stock market: An analysis of timevarying beta risks." Journal of International Financial Markets, Institutions and Money 25, 88-105.

Marcucci, J. (2005). "Forecasting Stock Market Volatility with Regime-Switching GARCH Models." Studies in Nonlinear Dynamics \& Econometrics 9, no. 4.

Marshall, B. R, N. H Nguyen, and N Visaltanachoti. (2013). "Liquidity measurement in frontier markets." Journal of International Financial Markets, Institutions and Money 27, 1-12.

Metropolis, N, A.W Rosenbluth, M.N Rosenbluth, A.H Teller, and E Teller. (1953). "Equation of state calculations by fast computing machines." Journal of Chemical Physics 21, 1087-1092.
Mlambo, C, and N Biekpe. (2005). "Thin trading on African stock markets: Implications for market efficiency testing." Investment Analysts Journal 34, no. 61, 29-40.

MSCI Frontier Markets (2019). May 16, 2019. https://www.msci.com/market-classification.

Nelson, D. B. (1991). "Conditional Heteroskedasticity in Asset Returns: A New Approach." Econometrica, 347-370.

Ozdemir, S, and I Akgul. (2015). "Inflationary effects of oil prices and domestic gasoline prices: Markov-switching-VAR analysis." Petroleum Science 12, no. 2, 355-365.

Quisenberry Jr, C, and B Griffith. (2010). "Frontier equity markets: A primer on the next generation of emerging markets." The Journal of Wealth Management 13, no. 3, 50-58.

R Core Team. (2018). R: A language and environment for statistical computing. Vienna, Austria: R Foundation for Statistical Computing.

Samarakoon, L. P. (2011). "Stock market interdependence, contagion, and the US financial crisis: The case of emerging and frontier markets." Journal of International Financial Markets, Institutions and Money 21, no. $5,724-742$.

Shleifer, A, and R Vishny. (2011). "Fire sales in finance and macroeconomics." Journal of Economic Perspectives 25, no. 1, 29-48.

Spiegelhalter, D.J, N.G Best, B. P Carlin, and A Van Der Linde. (2002). "Bayesian measures of model complexity and fit." Journal of the Royal Statistical Society: Series B (Statistical Methodology) 64, no. 4, 583-639.

Sukumaran, A, R Gupta, and T Jithendranathan. (2015). "Looking at new markets for international diversification: frontier markets." International Journal of Managerial Finance 11, no. 1, 97116.

Uyaebo, S. O, V. N Atoi, and F Usman. (2015). "Nigeria stock market volatility in comparison with some countries: Application of asymmetric GARCH models." CBN Journal of Applied Statistics 6, no. 2, 133-160. 
Van Gysen, M, C. S Huang, and R Kruger. (2013). "The performance of linear versus non-linear models in forecasting returns on the Johannesburg Stock Exchange." The International Business \& Economics Research Journal (Online) 12, no. 8,985 . 